\title{
Reader Response Theory in the Phenomenology of Reading with the text and the reader as its focal point
}

\author{
Mohammed Abdullah Mohammed Al-Haba \\ School of Language, Literature and Culture Studies SRTM University, Nanded (M.S)
}

\begin{abstract}
A literary work used to be looked at and received as the product of the writer's own horizon, imagination and aesthetic creativity. This conception of the text focused on and tried to understand a single meaning allocated to the text and that fixed and final meaning is nothing but the intention of the author of the text. It was claimed that responses to the same text would necessarily have to be the same albeit at different times and by different readers. The text was doomed to a pregiven and single meaning and unchangeable reality prior to it. Yet, twentieth century criticism has drawn a considerable attention and critical importance to the possibility that responses and interpretations to a given text evolve and develop from time to time and from reader to another reader. The approach of this theory which is called reader response theory in the phenomenology of reading revolves around the text and the reader and argues that the relationship between them is ontological in its nature. Ontological in the sense that a written text must have a reader and that the reader lends genuine value to the text. This paper is going to explore how, according to this theory, a text is open to meanings and is capable of producing different responses.
\end{abstract}

Keywords: Phenomenology of reading, reader response theory, reader and the text

\section{Introduction}

With the predominant and prevailing mode of objectivism and formalism, the reader-response theory and the foundations of phenomenology were established to challenge the formalist assertion of the objectivity of the text and "The text itself" became the battle cry of the New Critical effort to focus our attention on the literary work as the sole source of evidence for interpreting it (Lois Tyson, 136).

In the late 1960s and early 1970s there arose in Germany in Konstanz University a reader-response or "reception" theory. This theory asserts that the reader has received no attention and that an author or a piece of writing requires a reader. The theory has raised a number of questions: is there a difference between a read and an unread text? What is reading? Is reading a bonus conceded to the text? Is it a favour done to the author? Does a text suffer if it is not read? The answer to all these questions is provided through many conceptions and formulations about reading. The phenomenological theory of reading is the primal theory and it focuses exceptionally on the text, the reader's access to the text and the nature of that access.

\section{Phenomenology of Reading}

The Greek word phainomenon means "appearance." Hence, as a philosophical attitude, phenomenology shifts our emphasis of study away from the "external" world of objects toward examining the ways in which these objects "appear" to the human subject, and the subjective contribution to this process of appearing (Habib, 709). The task of phenomenology, then, is to examine not the world of objects "in itself" but how this world is constituted by a vast range of acts of consciousness. Husserl attempted to construct a philosophy of "pure subjectivism" and he opposed "naturalism". He disposed of psychologism in all its forms, along with all the admittedly faulty naturalism of his time (Marvin Farber, 4, 5).

Husserl objects to the belief of the common man in the independent existence of things in the outside world and that what we know of them is reliably true, despite the fact that "we cannot be sure of the independent existence of things, Husserl argues, we can be certain of how they appear to us immediately in consciousness, whether the actual thing we are experiencing is an illusion or not (Eagleton, 48)." It means that there is a relationship between objects and human consciousness.

All objects have externalities, an empirical meaning and can be explained in external, empirical or textual terms. Objects exist in the fullness of that meaning, Husserl argues, "we cannot be sure of the nature of the outside world; but we can have certainty about the nature of our own perception and about the ways in which we construct the world, the ways in which that world appears to our subjective apparatus," (Habib, 709). They have a stretch of empirical meaning and every object is conscious-bound. Objects deliver the fullest meaning and deserve their fullest identity in the world of appearance, "Doubtless what I glimpse through the words are mental forms not divested of an appearance of objectivity. But they do not seem to be of a nature other than my mind which thinks them," (Norton Anthology, 1322). 
Consciousness is always a consciousness of something; there is no empty consciousness. Heidegger argues that "our consciousness both projects the things of the world and at the same time is subjected to the world by the very nature of existence in the world," (Raman Selden, 62). Human consciousness is always conscious of something and this oftness of consciousness in phenomenology is called 'intentionality' or 'noesis' which generally means the activity of the mind. Consciousness is not independent of objects; it carries objects.

There is no an unintended object in the world and the fullest meaning of an object exceeds its empirical existence and becomes an appearance in the consciousness. We can delay questions about the definitive reality or knowability of the world and explain the world as it is given to consciousness. To know the essence of an object, you need to practice "bracketing" which means that you have to suspend the empirical structure and identity of an object and focus on the lines upon which the object comes to be an appearance, "This 'bracketing' of the external world is referred to by Husserl as the 'phenomenological reduction,' and it underlies his attempt to achieve certainty in philosophy," (Habib, 709). Phenomenology is beyond the external or the empirical:

Phenomenology examined not just what I happened to perceive when I looked at a particular rabbit, but the universal essence of rabbits and of the act of perceiving them. It was not, in other words, a form of empiricism, concerned with the random, fragmentary experience of particular individuals; neither was it a kind of 'psychologism', interested just in the observable mental processes of such individuals. It claimed to lay bare the very structures of consciousness itself, and in the same act to lay bare the very phenomena themselves, (Eagleton, 49).

Phenomenology should make an appearance and an experience in consciousness. It does not just disclose which is quite external, it debases and malforms the self-sense, for it is concerned first and foremost with a stretch of meaning into consciousness. It conceptualizes a literary text as incomplete which attains its completeness only when it is read. This shift of the theory gave rise to what came to be known as the reception theory or Reader- Response Theory in the phenomenology of reading which argues that those literary texts, though written, still have incomplete meaning. They are deemed incomplete and indeterminate and wait for reading to gain completion.

\section{Reader response theory}

Reader response theory of literature is concerned primarily with the ontology of a literary text in which the reader is integral to the text as an ontological value. Iser contends that, "a literary text can only produce a response when it is read," (Wolfgang Iser, 1). It is a mode of an existence of a literary text in which the text is not autonomous and must have a reader. This theory carries an intrinsic or a readerly invitation to the reader.

Reader response in literary theory conceptualizes a literary text as incomplete which attains its completeness only when it is read and Iser says that, "some elements of the text are indeterminate and their meaning must be worked out by the reader," (Habib, 728). It is indeterminate by being merely written and can be activated into meaning only when it becomes an appearance in the consciousness of the reader. Reading, for the phenomenology theory of literature, is a concretization of a literary text. This theory raises the question; "Does writing require reading?" And provides a definite answer of a resounding yes and a reader, too.

It is an anti-realist theory of literature for in the realist text, the reader has rarely to recover or reexperience where the reader is a mimetic reader. It is like a commonsensical text to a commonsensical reading under the assumption that the text has a single meaning of which Iser objects saying that the meaning of a text is not a fixed and 'definable entity' but 'a dynamic happening,'( Habib, 728).

The phenomenological reader reproduces the meaning for the meaning to him is indeterminate and this indeterminacy, Iser says, "conditions the interaction between text and reader, and such a two-way process cannot be called arbitrary" (Habib, 728). In this way, literary texts initiate "performances" of meaning "rather than actually formulating meanings themselves," (Habib, 728).

Gadamer argues that "a literary work does not pop into the world as a finished and neatly parcelled bundle of meaning; rather meaning depends on the historical situation of the interpreter," (Raman Selden, 62). The reason for that is that writing "books are like a picnic to which the author brings the words and the reader the meaning," (Wolfgang Iser, 19). Such a reader is called, "implied reader."

\section{Reader and the text}

The act of writing prior to reading is a scheme of triggers, guidelines, instructions and a body of incomplete meaning to the reader which makes the text ontologically prescribe a role for the reader. The implied reader refers to the act of reading a book or a piece of writing required as a response to the scheme, triggers, etc, which are ontologically calling for a reading. This implied reader is actually invited by the text and the implied reader the text addresses has some "characteristics we can deduce by studying the style in which the text is written and the apparent "attitude" of the narrative toward the reader", (Lois Tyson, 187). 
This scheme takes many forms in a literary text such as disconnected details, promptings, gaps, etc. The designation for all this scheme, triggers, promptings, etc, is the 'implied reader.' Nonetheless, it should be clear that there is no grand absolute and universal 'implied reader'; there will be as many implied readers as there are many different texts. Each text has its own implied reader and that is why we cannot read all the texts comfortably and/ or equally because the consciousness is structured to respond to the schemes and triggers of a specific writing.

All reading is selective and the requirements of a text do not apply to all implied readers. The implied reader has to actualize the text and because "the text's structure allows for different realizations and interpretations, any one actualization, says Iser, "represents a selective realization of the implied reader," (Habib, 731).

Likewise, there is what Wayne Booth calls in his book Rhetoric of Fiction 'the implied author' which is a term that refers to the artistic image of the author of a literary work and not the historical image. Writing carries the artistic personae of the writer, the artistic 'second self'.

The author of a literary work "creates not simply an ideal, impersonal "man in general" but an implied version of "himself," (Wayne Booth, 70). Though implied authors differ from a text to another text because in some texts the authors "were discovering or creating themselves as they wrote", and "for regardless of how sincere an author may try to be, his different works will imply different versions, different ideal combinations of norms," (Wayne Booth, 71), they remain to be artistic images of authors.

Once the literary text is written, it is not enough. It must be read and it must have a reader because writing is an expectation of reading and meaning. Formalists say that the meaning of a text "is located in the forms and verbal structures of a text" and neglect the reader's experience of the text. Stanley Fish opposes to that and admits that the reader he has in mind is the "reader whose education, opinions, concerns, linguistic competences ... make him capable of having the experience the author wished to provide," (Habib, 734).

The main notion of Fish rests on intersubjectivity as opposed to formalists and he contends that "facts do not exist independently of, or prior to, the interpretations and viewpoints that construct them as such," (Habib, 735). He insists that "this process of constructing or "writing" the text is equivalent to grasping, in a temporal fashion, the author's intention, which is itself a product of interpretation," (Habib, 735). Fish argues that "a text is not an object, a thing in itself, but something that happens to and with the participation of the reader." He says that a literary text has textual linearity that will not be smooth and fluid.

It has to be defamiliarized with complexity of semantic and static experience. It takes time to cope with linearity and negotiate with it which is called, 'temporality of reading.' Reading, for Fish, is not a transitive means to an end to meaning; the act of reading is the end and the meaning of the text and that the meaning of a literary text is the temporality of reading coping with its textual linearity.

The phenomenology of reading is existential in which whatever you experience while reading is part of the whole meaning, since meaning is an event and by event it means the temporal movement of the reader's cognition (word after word, line after line, sentence after sentence, etc,) (from moment to moment, day to day, week to week, etc,) of negotiating with the textual linearity of the text. Stanley Fish claims that the active reading is the meaning of a text, 'meaning is event.' The text entails twists and turns, loops, leaps and jumps, ups and downs and that the meaning of the text is 'bliss' which is the pain and cognitive stress involved in a text reading.

The term 'text of bliss', 'text scriptable' or 'writerly text' is a term used to describe a difficult text to read. Barthes argues that the text makes the task of reading "active, productive, and constitutive. The text "requires that one try to abolish ... the distance between reading and writing . . . by joining them in a single signifying practice. It is called so because it invites distressful act of reading," (Habib, 647). He defines a text of bliss as, "the text that imposes a state of loss, the text that discomforts, unsettles the reader's assumption and brings to a crisis his relation with language.' Such a text is not a text of 'bliss' just because it is difficult to read; it is so because it pleases us and "the pleasure we derive from the work, says Barthes, is nonetheless the pleasure of consumption: we do not participate in the production, we do not rewrite. The text, on the other hand, "is bound to jouissance," to bliss or ecstasy, to "a pleasure without separation," (Habib, 648).

The act of reading for the phenomenology of literature is intransitive which comes in a striking tradition of a literary language that is not fatefully tied to a reality prior to it, but is all the reality we know; it is self-referential. Language distinctively is not obedient to a reality prior to it which makes the language another reality. In the poetic function, language establishes its own reality and more importantly language itself as reality. It exists in a special relationship with itself.

Phenomenology has an intransitive conceptualization of reading. It is anti-theological for it delinks meaning from a prior reality or origin and, therefore, the conceptualization of language and meaning is also antitheological. It promotes multi-readings because in the theological transitive theory, you are closing the meaning and/ or language in a prior reality, origin and ground. The closure of meaning in a single and fixed meaning 
proscribes other meanings and consequently the meaning gets authoritarian. Iser contends that "different readers are free to actualize the work in different ways, and there is no single correct interpretation which will exhaust its semantic potential," but he stipulates that "the reader must construct the text so as to render it internally consistent," (Terry Eagleton, 70).

Roman Ingarden states "that literary works form organic wholes, and the point of the reader's filling in their 'indeterminacies' is to complete this harmony," (ibid, 70). For Ingarden, "The text comes ready equipped with its indeterminacies, and the reader must concretize it 'correctly," (ibid, 70). What seems common between Ingarden and Iser is the emphasis on and importance of the consistency and coherence of the parts to the whole which shows to us "the influence of Gestalt psychology, with its concern to integrate discrete perceptions into an intelligible whole," (ibid, 70).

Gestalt psychology argues that "the human mind does not perceive things in the world as unrelated bits and pieces but as configurations of elements, themes, or meaningful, organized wholes," (Raman Selden, 57). The text is inexhaustible and has the potential multiplicity of connections. By that we admit that a literary text can exceed any number of readings. Iser sees:

The polysemantic nature of the text and the illusion making of the reader as "opposed factors," but both are necessary in the process of reading: if the illusion were destroyed completely, the text would be alien to us; and if the illusion were all embracing, then the polysemantic nature of the text would be reduced to one level of meaning. Hence we try to find a balance between these two conflicting tendencies. According to Iser, however, the "dynamism" of the text, its sense of life-likeness, presupposes that we do not actually achieve this balance. Even as we seek a consistent pattern in the text, we are also uncovering other textual elements and connections that resist integration into our pattern (Habib, 726).

Reflecting on this quotation, the vacillation between fully destroying and fully preserving the illusion leads to the alienation of the text to the reader. So, since the reader does not succeed in achieving a balance, the alienation does exist and continues in the form of 'other textual elements' and 'connections.'

\section{References}

[1] Booth C. Wayne, The Rhetoric of Fiction, The University of Chicago Press, Chicago and London.

[2] Brownell Philip, A guide to Contemporary Practice, Gestalt Therapy, Springer Publishing Company, New York.

[3] Eagleton Terry, Literary Theory- An Introduction, Blackwell Publishing, 350 Main Street, Malden, USA, 1996.

[4] Farber Marvin, The Foundation of Phenomenology, State University of New York Press, Albany, New York, 1943.

[5] Iser Wolfgang, The Act of Reading.

[6] Iser Wolfgang, The Range of Interpretation, Colombia University Press, New York.

[7] M.A.R Habib, Modern Literary Criticism and History, Blackwell Publishing Limt, USA, 2005.

[8] Norton Anthology of Theory and Criticism, Norton and Company Inc. New York, 2001.

[9] Selden Raman, A Reader's Guide to Contemporary Literary Theory, Great Britain, 2005.

[10] Tyson Lois, Critical Theory Today, Taylor and Francis Group, 270 Madison Avenue, New York, 1950. 